\title{
The Research on Impulsive Events in Railway Noise Generated During Passage Through a Railroad Switch
}

\author{
Bartłomiej KUKULSKI, Tadeusz WSZOŁEK \\ AGH University of Science and Technology \\ Faculty of Mechanical Engineering and Robotics \\ Department of Mechanics and Vibroacoustics \\ Al. Mickiewicza 30, 30-059 Kraków, Poland; e-mail: \{kukulski, twszolek\}@agh.edu.pl
}

(received February 2, 2016; accepted March 29, 2017)

\begin{abstract}
This paper presents the result of research on the impulsive components of a railway noise generated during passage through a railroad switch compared with a typical rail noise and evaluation of this phenomenon with particular emphasis on impulsive sounds. The study includes the analysis of the source of impulsive components in the railway noise, the methodology of measurement and data analysis. Spectral analysis of typical fragments passing through a railroad switch is given together with a proposal of additional indicators to assess the noise. Authors propose three descriptors of the impulsive noise such as spectral centroid, kurtosis and impulsiveness, and show that these descriptors can be useful in assessment of the impulsive noise generated during trains' crossing.
\end{abstract}

Keywords: impulsive noise; railway noise measurements; impulsiveness.

\section{Introduction}

Contemporary models of railway noise base on one parameter - equivalent sound level $L_{\text {Aeq, } T \text {, which is }}$ calculated for a specific number of rides. These models completely omit, or include in a simplified manner, the impact of certain events such as squeaks when train brakes, or rides through railroad switches and joints that generate the characteristic "knocks", which is an example of impulsive noise. In practice, such phenomena will not significantly affect total value of equivalent sound level $L_{\text {Aeq, } T}$, however, they are a cause of increased local acoustic annoyance, which can be significant (KUKULSKI, 2013).

From the point of view of the annoyance of railway noise, rating levels could be introduced to reflect the occurrence of additional factors that increase noise annoyance (WszoŁEK, 2015) such as tonality (squeals from braking and rubbing on curves) and impulsiveness (WszoŁeK, Koter, 2015).

Railroad switches are usually placed in an enclosed area of a train station, but the noise generated by the frequent movement of trains can be disruptive for passengers and workers. Therefore, it seems to be reasonable to take into account the impulsive factor during calculating the indicators of railway noise in areas with a large number of railroad switches. The correct determination of the adjustment values should result in a more adequate assessment of its annoyance. The presence of impulses at each railway switch is a need for applying impulsive adjustment in determining the long-term sound levels, the day-evening-night level $L_{\text {den }}$ and equivalent level $L_{\text {Aeq, } T}$.

Analysis of the components of rail noise can distinguish three common types: rolling noise, which dominates for speeds below $250 \mathrm{~km} / \mathrm{h}$, the aerodynamic noise for higher speeds, and characteristic impulsive "knocks" occurring when trains passes railroad joints and switches (ThOMPson, 2009). Modern computational models, eg. Harmonoise or models recommended in the Directive END (2002/49/EC European Noise Directive, 2002), do not include the third of these types of noise, despite the fact that they should be considered when calculating noise indicators and giving them the appropriate impulsive adjustment (VERHEIJEN, 2004; Verheijen, PAVIotti, 2003).

The aim of this paper is to demonstrate that the impulsive noise during passage through the railroad switches exists and it should be taken into account in the final assessment of noise annoyance. As the impulsiveness is random in nature, depending on many factors (also random), authors are looking for measurable 
parameters to differentiate signals according to their annoyance for further application of impulsive adjustment. For that purpose, some known descriptors were proposed. The holistic approach to the problem extends far beyond the area of this paper and it was not the intention of the authors.

\section{Material and methods}

The study material consists of a series of experimental measurements of the acoustic parameters measured in Kraków Główny Railway Station. Railway switches are located approximately 50 meters from the platforms in the northern part of the station, inaccessible to travellers. Railroad switch group consists of four double and three single turnouts. Kraków Główny Railway Station operates three main types
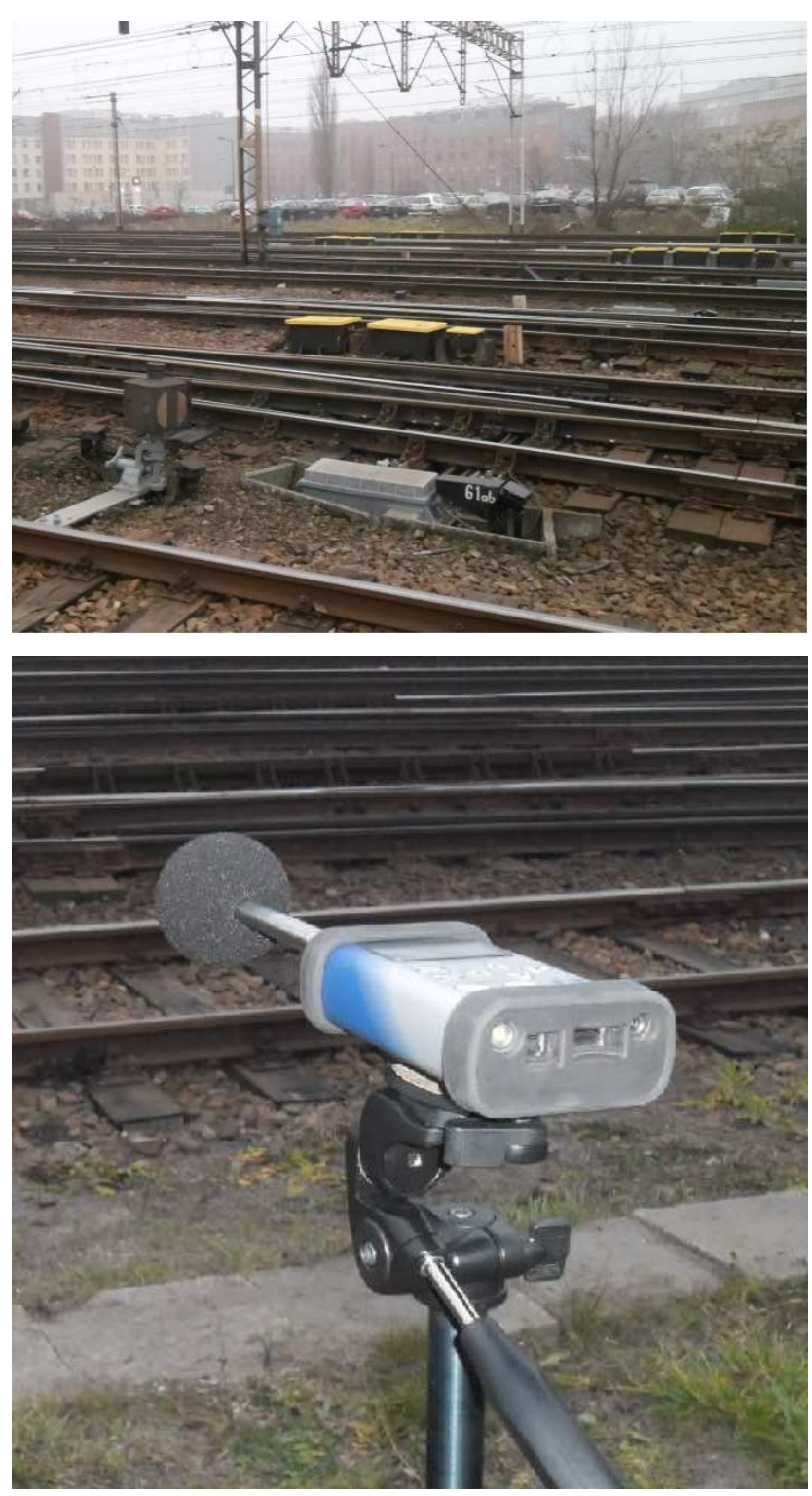

Fig. 1. Measurement place and equipment. of trains: long-distance passenger trains: locomotives with couches 111A, regional passenger trains EN57 or EN71, and railbuses SA109-002 designed to support connections with the airport Kraków Balice. For the further analysis 45 runs of trains were recorded -15 for each type.

The measurement point was set $7.5 \mathrm{~m}$ from the centre of the railroad switch. Measuring devices were placed at a height of $1.5 \mathrm{~m}$, according to Regulation of the Minister of Environment (2011; 2014). Sound level meter Svan 959 was used for the registration of the sound pressure level for calculation of acoustic parameters: $L_{\mathrm{Aeq}}, L_{\mathrm{AE}}, L_{\mathrm{A} \max }, L_{\mathrm{A} \text { min }}$, statistical parameters $L_{\mathrm{A} 10}, L_{\mathrm{A} 50}, L_{\mathrm{A} 90}$ and for the $1 / 3$ octave bands multi spectrum measured from $10 \mathrm{~Hz}$ to $20 \mathrm{kHz}$ and A-weighted sound levels with a time resolution $0.1 \mathrm{~s}$ with linear averaging (LIN) and peak value (PEAK) with time constant IMPULSE. Additionally, each run was recorded by audio recorder ZOOM H4n.

\section{Descriptors of railway noise}

\subsection{Rating levels}

Scientific studies (BERRY, BISPING, 1988; WSZOŁeK, 2015; WszoŁek, Koter, 2015) show that Aweighted equivalent sound level is insufficient to assess the noise annoyance characterized by high tonality, a large impulsiveness or increased content of lowfrequency components. In order to include the impact of the above factors in assessing the noise annoyance, standard (ISO 1996-1:2016) introduced the appropriate adjustments, and adjusted levels called rating levels, based on A-weighted equivalent level $L_{\mathrm{Aeq} j, T n}$ and A-weighted exposure level $L_{\mathrm{E} i j} . L_{\mathrm{RE} i j}$ - is a rating sound exposure level for assessment of the $i$-th single event and an adjustment $K_{j}$ (for the $j$-th source), excluding high-energy impulsive sounds or events with high content of low-frequency components.

$$
L_{\mathrm{RE} i j}=L_{\mathrm{E} i j}+K_{j},
$$

$L_{\text {Req, Tn }}$ - rating equivalent continuous level (A) over a time interval $T_{n}$ for the $j$-th source.

$$
L_{\mathrm{Req} j, T n}=L_{\mathrm{Aeq} j, T n}+K_{j} .
$$

Adjustment $K_{j}$ related to the nature of sound source must be used only for a time interval in which the impulsive character is present. In a typical impulse noise, measured as an equivalent level, rather than the individual noise event, the adjustment value equals $3 \mathrm{~dB}$. Tonality adjustment can be assigned and used by the algorithms in the standard (ISO 1996-2:2007).

\subsection{Spectral centroid}

Spectral centroid $\bar{x}$ is a first spectral moment. It shall be interpreted as a weighted average frequency for 
all frequency bands and is expressed in the following equation:

$$
\bar{x}=\frac{\sum_{i=1}^{N} w_{i} x_{i}}{\sum_{i=1}^{N} w_{i}},
$$

where $w_{i}$ - equivalent sound level in the $i$-th $1 / 3$ octave band, $x_{i}$ - center frequency of the $i$-th $1 / 3$ octave band.

Spectral centroid is useful in assessing the distribution of acoustical energy in spectrum bands with constant percentage bandwidth, reflecting especially presence of high frequencies - characteristic of the components of impulses.

\subsection{Kurtosis}

Kurtosis is a descriptor that determines the flatness of the spectrum bands. When dealing with a positive value of this indicator, signal distribution is heavily concentrated around the mean value. Negative kurtosis indicates poor concentration around the average, and thus flat spectrum, which would be expected in the case of impulsive noise. Kurtosis is determined by the following formula:

$$
\operatorname{Kurt}=\frac{\frac{1}{N} \sum_{i=1}^{N}\left(x_{i}-\mu\right)^{4}}{\sigma^{4}}-3,
$$

where $N$ - sample size, $x_{i}$ - equivalent sound level for the $i$-th frequency band, $\mu$ - mean value (expected value) of the sample, $\sigma$ - standard deviation of the sample.

\subsection{Impulsiveness}

Impulsiveness can be evaluated according to the definition given in Eq. (5) (HAMERNIK, HsUEH, 1991), where it is defined as the difference between peak sound pressure level, $L_{\text {Apeak }}$ and equivalent sound pressure level measured with a SLOW time constant $L_{\text {AeqS }}$. Weak inequality can be described as a threshold for considering events as highly impulsive or even as impulses with high-energy content

$$
I=L_{\text {Apeak }}-L_{\text {AeqS }} \geq 15 \mathrm{~dB},
$$

where $L_{\text {Apeak }}$ - peak sound pressure level measured with IMPULSE time constant $[\mathrm{dB}], L_{\mathrm{AeqS}}-$ equivalent sound pressure level as measured with a SLOW time constant $[\mathrm{dB}]$.

Impulsiveness parameter can be used to assess impulses to qualify them to the appropriate category with appropriate adjustments in accordance with standard (ISO 1996-1:2016), whether impulses can be measured as a single events, or as a series, where single impulses cannot be easily distinguished.

This standard proposes three types of impulsive sources:

- high-energy impulsive sound source,

- highly impulsive sound source,

- regular impulsive sound sources.

There is no clear criterion for qualifying of these sounds (except as described above) in the mentioned standard, and the adjustment value can be applied from 3 to $12 \mathrm{~dB}$.

\section{Analysis of the noise coming from passing the railway switch}

A single passage through a railroad switch can be easily distinguished from the typical railway noise generated during ride through straight tracks because of the accompanying characteristic "knocks". Differences in registered during this crossing equivalent sound level are even over a dozen decibels within half of a second. In the moment of impact of the wheel on the rail, an impulsive sound is generated with sound pressure level $L_{\mathrm{A}}$ (equivalent sound pressure level for $0.1 \mathrm{~s}$ elementary time interval of recording of the whole passage), which can exceed $90 \mathrm{~dB}$. Simultaneously, after this impact, $L_{\mathrm{A}}$ drops to around $75 \mathrm{~dB}$. For a typical ride, these differences do not exceed three decibels. Time domain comparison of equivalent sound levels of regional passenger trains EN57 is presented in Fig. 2.

Presented in the Table 1 equivalent levels $L_{\text {Aeq, }} T$ and exposure levels $L_{A E}$ (for a whole passage through a railroad switch) designated for a "typical" ride are smaller than rating levels $L_{\mathrm{Req}}, 1 \mathrm{~h}$ and $L_{\mathrm{RE}}$ describing

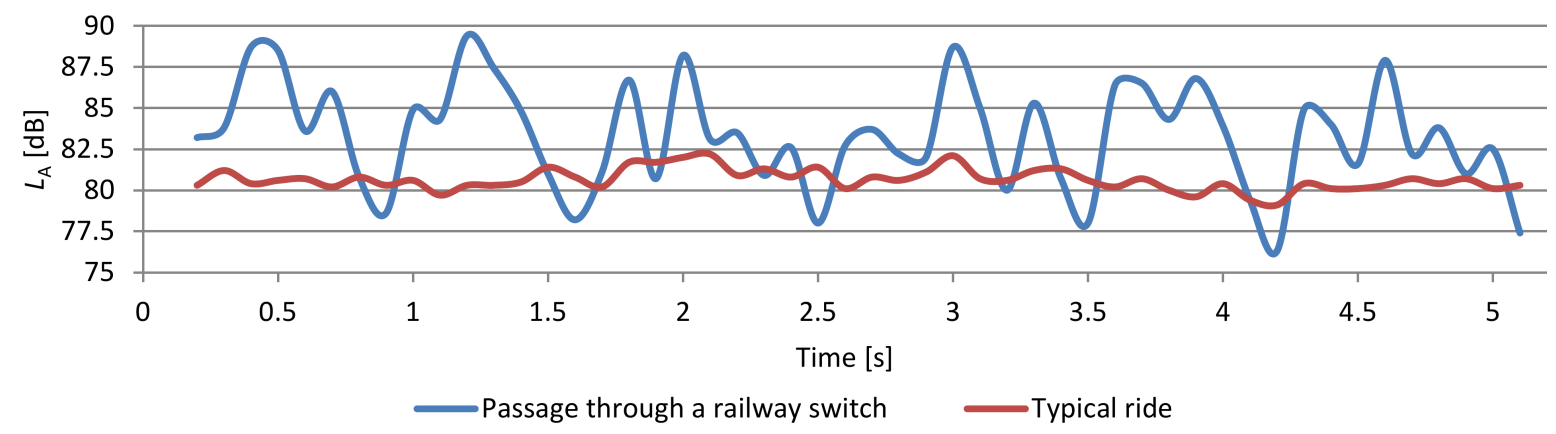

Fig. 2. Time domain comparison of equivalent sound levels of regional passenger trains EN57. 
Table 1. Comparison of $L_{\mathrm{Aeq}, T}, L_{\mathrm{AE}}$ for a typical ride and rating levels $L_{\text {Req, } 1 \mathrm{~h}}, L_{\mathrm{RE}}$ for a ride through a railroad switch for three types of trains.

\begin{tabular}{|c|c|c|c|c|}
\hline \multirow{2}{*}{$\begin{array}{c}\text { Types } \\
\text { of trains }\end{array}$} & \multicolumn{2}{|c|}{ Typical ride } & \multicolumn{2}{c|}{$\begin{array}{c}\text { Passing through } \\
\text { the railway switch }\end{array}$} \\
\cline { 2 - 5 } & $\begin{array}{c}L_{\mathrm{Aeq}, T} \\
{[\mathrm{~dB}]}\end{array}$ & $\begin{array}{c}L_{\mathrm{AE}} \\
{[\mathrm{dB}]}\end{array}$ & $\begin{array}{c}L_{\text {Req, } 1 \mathrm{~h}} \\
{[\mathrm{~dB}]}\end{array}$ & $\begin{array}{c}L_{\mathrm{RE}} \\
{[\mathrm{dB}]}\end{array}$ \\
\hline I & 80.8 & 93.0 & 86.5 & 100.3 \\
\hline II & 76.2 & 88.2 & 82.8 & 92.1 \\
\hline III & 74.0 & 83.0 & 81.5 & 91.0 \\
\hline
\end{tabular}

I - locomotives with couches $111 \mathrm{~A}$,

II - regional passenger trains EN57,

III - railbuses SA109-002.

the passage of a train by railroad switch. There can be observed differences in sound levels between 6 and $8 \mathrm{~dB}$ for rail buses and locomotives with couches. For regional passenger trains difference occurs around $4 \mathrm{~dB}$. The mean values of $L_{\mathrm{Aeq}, T}, L_{\mathrm{AE}}, L_{\mathrm{A} \max }, L_{\mathrm{A} \text { min }}$ given for each type of train while passing through a railway switch are presented in Table 2. These values complement the determination of the average value of the impulsiveness parameter $I$, which is in the range of 15 $20 \mathrm{~dB}$, which indicates that the ride of a train through a railroad switch has definitely impulsive nature.
Table 2. Comparison of mean values of parameters $L_{\text {Aeq, } T}$, $L_{\mathrm{AE}}, L_{\mathrm{A} \max }, L_{\mathrm{A} \text { min }}$ and impulsiveness $I$ for a passage through a railroad switch for three types of trains.

\begin{tabular}{|c|c|c|c|c|c|}
\hline $\begin{array}{c}\text { Types } \\
\text { of trains }\end{array}$ & $\begin{array}{c}L_{\mathrm{Aeq}, T} \\
{[\mathrm{~dB}]}\end{array}$ & $\begin{array}{c}L_{\mathrm{AE}} \\
{[\mathrm{dB}]}\end{array}$ & $\begin{array}{c}L_{\mathrm{A} \max } \\
{[\mathrm{dB}]}\end{array}$ & $\begin{array}{c}L_{\mathrm{A} \text { min }} \\
{[\mathrm{dB}]}\end{array}$ & $\begin{array}{c}I \\
{[\mathrm{~dB}]}\end{array}$ \\
\hline I & 83.5 & 97.3 & 90.3 & 62.4 & 15.6 \\
\hline II & 76.8 & 89.1 & 82.7 & 61.3 & 19.6 \\
\hline III & 77.5 & 88.0 & 86.3 & 57.4 & 18.8 \\
\hline
\end{tabular}

I - locomotives with couches $111 \mathrm{~A}$,

II - regional passenger trains EN57,

III - railbuses SA109-002.

The $1 / 3$ octave band spectrum of passing through a railroad switch consists of three "distinctive" frequency bands: low frequencies: 25-63 Hz, rolling noise: 200$400 \mathrm{~Hz}$, and above all, $1600-2000 \mathrm{~Hz}$ coming from the impact of a wheel with loose rail junction - an impulsive component in the noise. In the typical ride spectrum band, e.g. 1600-2000 Hz, they are not as high as in the previous case. $1 / 3$ octave spectrum for a typical passage compared to passing through the railroad switch, measured for overall time of passage is presented in Figs. 3-5. Increased levels in the higher frequency bands indicate a shift of spectral centroid at higher frequencies.

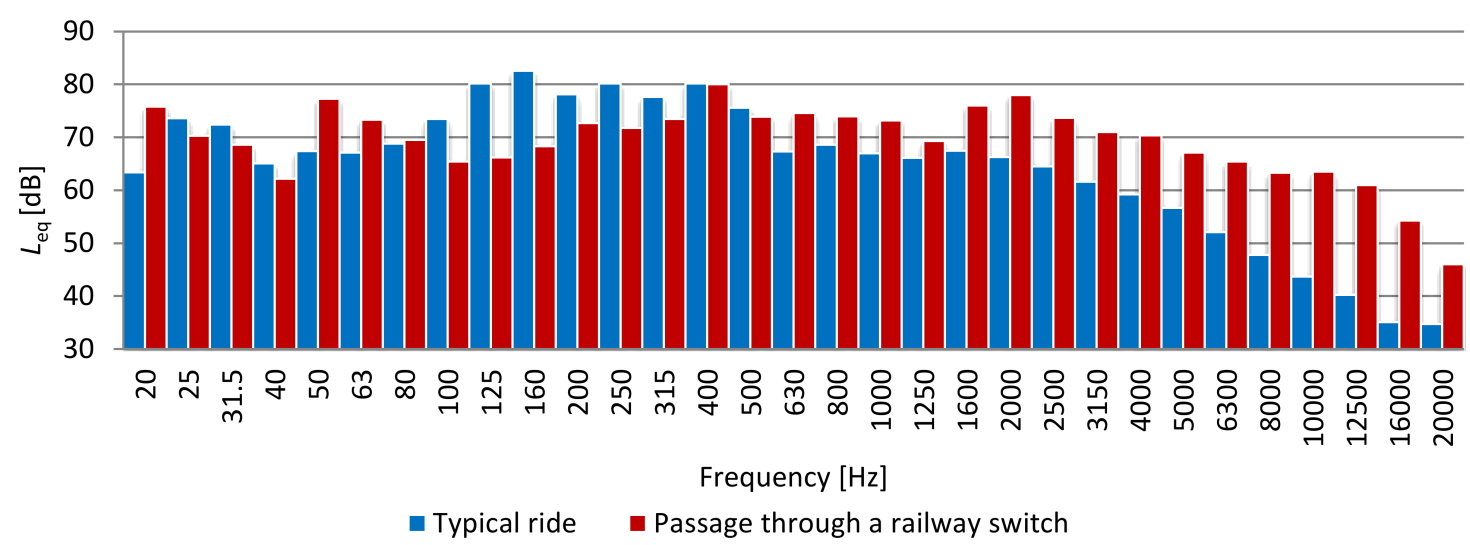

Fig. 3. 1/3 octave band spectrum for locomotives with couches 111A.

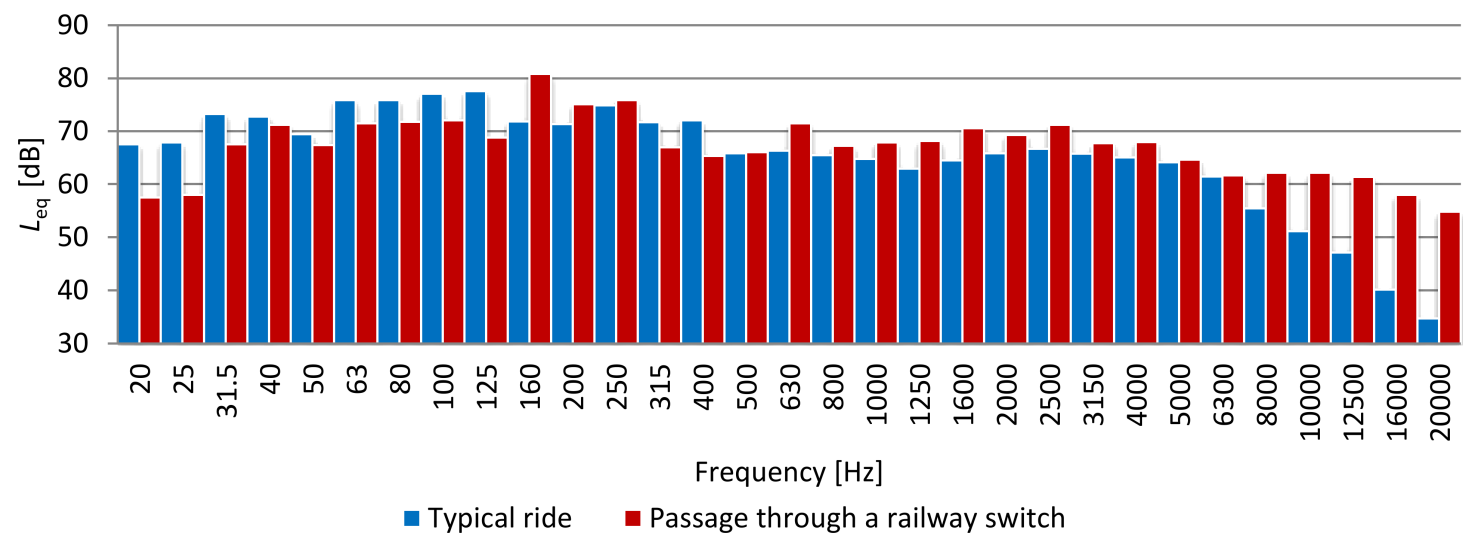

Fig. 4. 1/3 octave band spectrum for regional passenger trains EN57. 


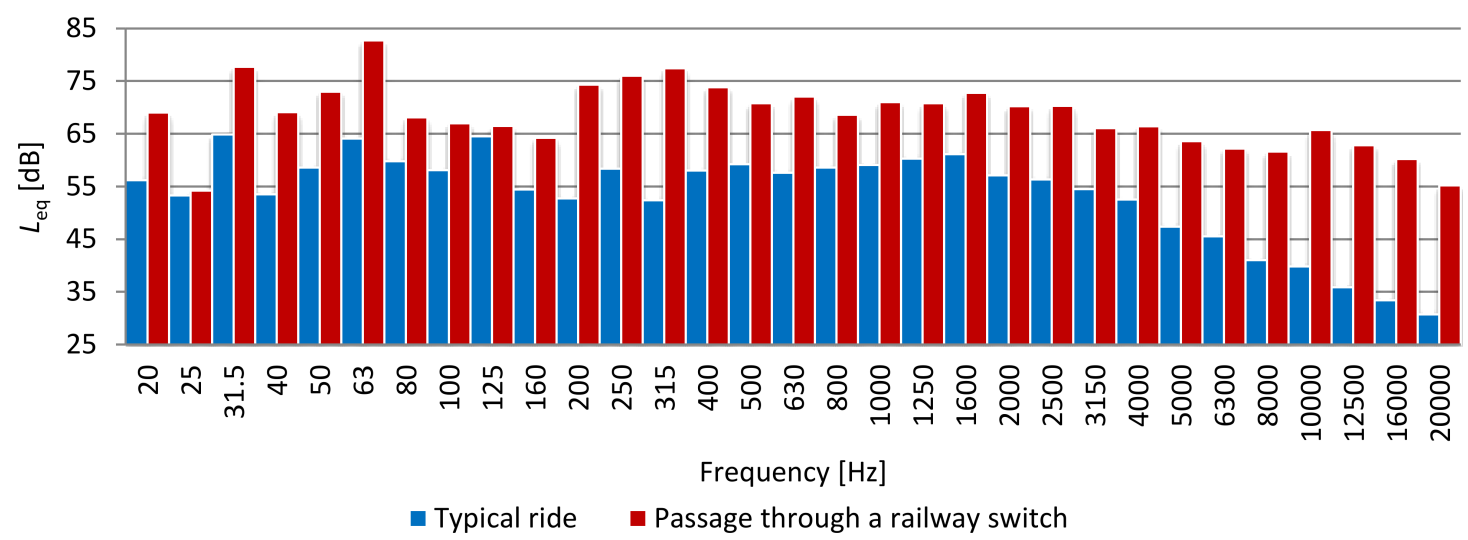

Fig. 5. 1/3 octave band spectrum for railbuses SA109-002.

\section{Analysis of the descriptors of railway noise}

For each ride spectral centroid was calculated together with its standard deviation. Average values for each of three types of trains, provided with accuracy of $0.1 \mathrm{~Hz}$ are presented in Table 3. Furthermore, in parentheses the center frequency of $1 / 3$ octave band to which the determined spectral centroid corresponds is presented. For a typical ride, the spectral centroid for locomotives with couches $111 \mathrm{~A}$ and for regional passenger trains EN57 are located in the band 500 and $800 \mathrm{~Hz}$. But for ride through a railroad switch, spectral centroid shifts to higher frequencies.

This result is dependent on the length of the train - the more wheels, the more impacts with the loose rail occurs, and thus, the excitation band of $1600 \mathrm{~Hz}$ affects result in the shift of the center of gravity to $1250 \mathrm{~Hz}$ bandwidth. In the case of railbuses, this parameter remains in the range $1000 \mathrm{~Hz}$, because of the fact that during this ride there are only a few excitations of the rail.

A negative value of the kurtosis for the first two types of train confirms flatness of the distribution and therefore, impulsiveness of the sound generated during the passage. The rail buses have a positive value of the kurtosis. That means that the frequency distribution is more dense than in a case of previous groups of trains.
Table 3. Comparison of two descriptors: spectral centroid and kurtosis for a typical ride and ride through a railroad switch.

\begin{tabular}{|c|c|c|c|c|}
\hline \multirow{2}{*}{$\begin{array}{c}\text { Types } \\
\text { of trains }\end{array}$} & \multicolumn{2}{|c|}{ Typical ride } & \multicolumn{2}{c|}{$\begin{array}{c}\text { Passing through } \\
\text { the railroad switch }\end{array}$} \\
\cline { 2 - 5 } & $\begin{array}{c}\text { Spectral } \\
\text { centroid } \\
{[\mathrm{Hz}]}\end{array}$ & Kurtosis & $\begin{array}{c}\text { Spectral } \\
\text { centroid } \\
{[\mathrm{Hz}]}\end{array}$ & Kurtosis \\
\hline $\begin{array}{c}\text { Locomotives } \\
\text { with } \\
\text { couches 111A }\end{array}$ & $\begin{array}{c}543.6 \\
(500)\end{array}$ & 0.135 & $\begin{array}{c}1310.6 \\
(1250)\end{array}$ & -0.617 \\
\hline $\begin{array}{c}\text { Regional } \\
\text { passenger } \\
\text { trains EN57 }\end{array}$ & $\begin{array}{c}805.4 \\
(800)\end{array}$ & 2.383 & $\begin{array}{c}1275.1 \\
(1250)\end{array}$ & -1.042 \\
\hline $\begin{array}{c}\text { Railbuses } \\
\text { SA109-002 }\end{array}$ & $\begin{array}{c}951.9 \\
(1000)\end{array}$ & 0.769 & $\begin{array}{c}947.4 \\
(1000)\end{array}$ & 4.988 \\
\hline
\end{tabular}

Figures 6-8 show the impulsiveness occurrence over time, given for each group of the trains. The threshold was set to $15 \mathrm{~dB}$ - the value that classified the signal as an impulsive sounds by the criterion given in Eq. (5) and it was marked by a red line. For both railbuses SA109-002 and regional passenger trains EN57, impulsiveness is present as a single peak that illustrates impacts between wheel and loose tracks.

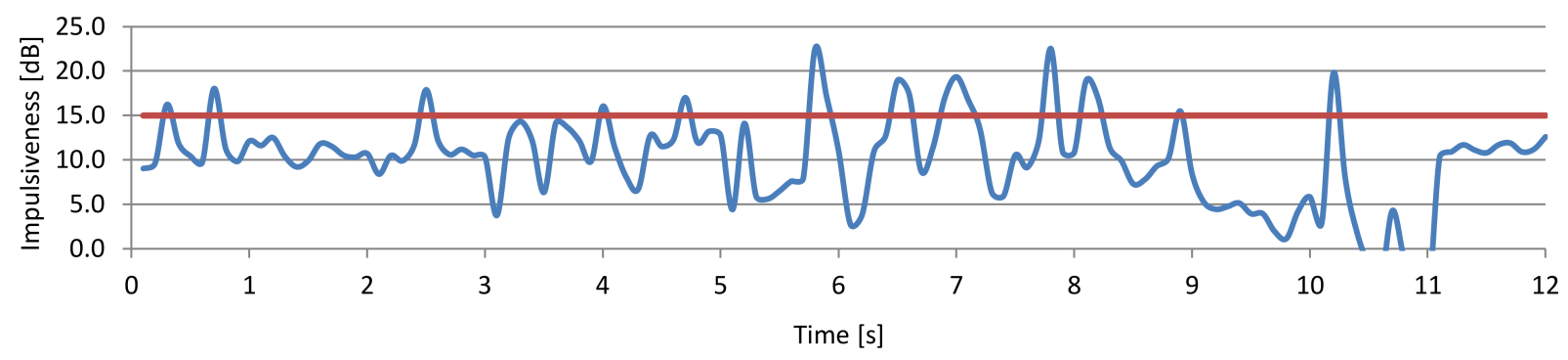

Fig. 6. Impulsiveness over time for railbuses SA109-002. 


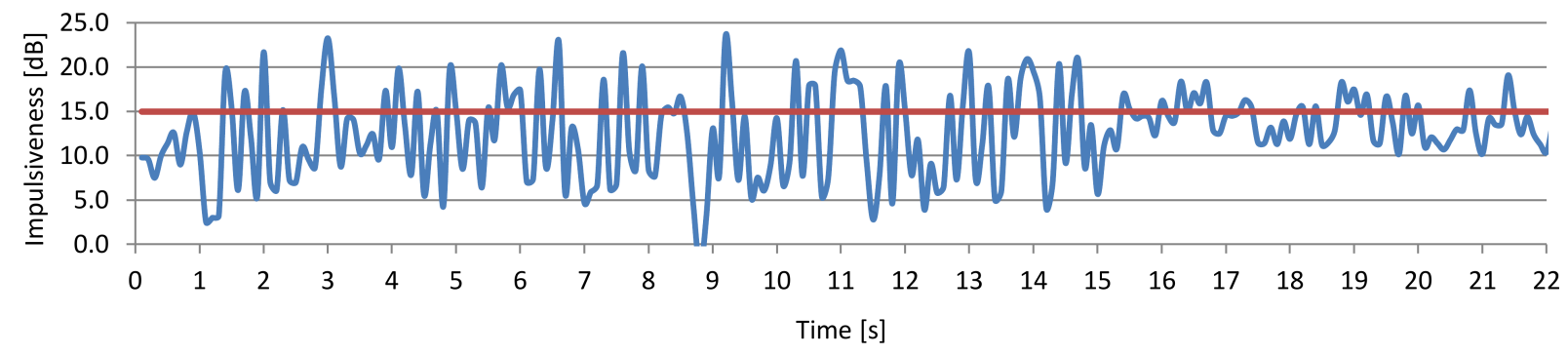

Fig. 7. Impulsiveness over time for locomotives with couches 111A.

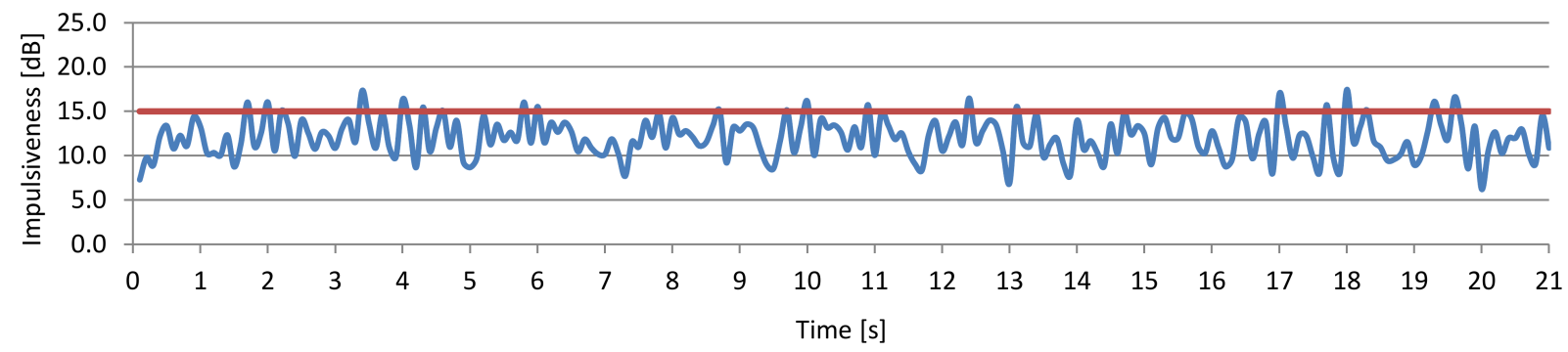

Fig. 8. Impulsiveness over time for regional passenger trains EN57.

Impulsiveness of the locomotives with couches exceeds the threshold value for almost the entire travel time.

The next step was to calculate the statistical levels $L_{10}, L_{50}$ and $L_{90}$ representing the noise descriptor that was surpassed by sequentially 10, 50 and 90 percent of ride time, calculated directly from SPL versus time. These parameters were calculated for the typical ride and for ride through a railroad switch. Impulsiveness quantiles $I_{90}, I_{50}, I_{10}$ represent 90,50 and 10 per cent of impulsiveness values over time of passage, calculated directly from every of $100 \mathrm{~ms}$ samples from the single passage. These values were derived from signals shown in Figs. 6-8. Low values for typical rides reflect no impulsive component for these events. On the other hand, "knocks" with impulsiveness value above $15 \mathrm{~dB}$ are present in at least 10 per cent of time of passage during railroad switch. The analysis results are presented in Tables $4-6$.

Table 4. Statistical noise levels $\left(L_{\mathrm{A} 90}, L_{\mathrm{A} 50}\right.$ and $\left.L_{\mathrm{A} 10}\right)$ and statistical impulsiveness levels $\left(I_{90}, I_{50}\right.$ and $\left.I_{10}\right)$ for locomotive with couches $111 \mathrm{~A}$ during typical ride and ride through a railroad switch.

\begin{tabular}{|c|c|c|}
\hline $\begin{array}{c}\text { Levels } \\
{[\mathrm{dB}]}\end{array}$ & Typical ride & $\begin{array}{c}\text { Passing through } \\
\text { the railroad switch }\end{array}$ \\
\hline \multicolumn{3}{|c|}{$L_{\mathrm{A}}$} \\
\hline$L_{\mathrm{A} 90}$ & 80.1 & 78.6 \\
\hline$L_{\mathrm{A} 50}$ & 80.6 & 83.5 \\
\hline$L_{\mathrm{A} 10}$ & 81.5 & 87.9 \\
\hline \multicolumn{3}{|c|}{ Impulsiveness, $I$} \\
\hline$I_{90}$ & 0.1 & 7.7 \\
\hline$I_{50}$ & 0.5 & 12.2 \\
\hline$I_{10}$ & 1.3 & 17.7 \\
\hline
\end{tabular}

Table 5. Statistical noise levels $\left(L_{\mathrm{A} 90}, L_{\mathrm{A} 50}\right.$ and $\left.L_{\mathrm{A} 10}\right)$ and statistical impulsiveness levels $\left(I_{90}, I_{50}\right.$ and $\left.I_{10}\right)$ for regional passenger trains EN57 during typical ride and ride through a railroad switch.

\begin{tabular}{|c|c|c|}
\hline $\begin{array}{c}\text { Levels } \\
{[\mathrm{dB}]}\end{array}$ & Typical ride & $\begin{array}{c}\text { Passing through } \\
\text { the railroad switch }\end{array}$ \\
\hline \multicolumn{3}{|c|}{$L_{\mathrm{A}}$} \\
\hline$L_{\mathrm{A} 90}$ & 75.2 & 70.2 \\
\hline$L_{\mathrm{A} 50}$ & 76.0 & 77.4 \\
\hline$L_{\mathrm{A} 10}$ & 78.2 & 79.9 \\
\hline \multicolumn{3}{|c|}{ Impulsiveness, $I$} \\
\hline$I_{90}$ & 0.1 & 9.6 \\
\hline$I_{50}$ & 0.6 & 12.0 \\
\hline$I_{10}$ & 1.6 & 14.6 \\
\hline
\end{tabular}

Table 6. Statistical noise levels $\left(L_{\mathrm{A} 90}, L_{\mathrm{A} 50}\right.$ and $\left.L_{\mathrm{A} 10}\right)$ and statistical impulsiveness levels $\left(I_{90}, I_{50}\right.$ and $\left.I_{10}\right)$ for railbuses SA109-002 during typical ride and ride through a railroad switch.

\begin{tabular}{|c|c|c|}
\hline $\begin{array}{c}\text { Levels } \\
{[\mathrm{dB}]}\end{array}$ & Typical ride & $\begin{array}{c}\text { Passing through } \\
\text { the railroad switch }\end{array}$ \\
\hline \multicolumn{3}{|c|}{$L_{\mathrm{A}}$} \\
\hline$L_{\mathrm{A} 90}$ & 58.1 & 57.8 \\
\hline$L_{\mathrm{A} 50}$ & 63.2 & 69.2 \\
\hline$L_{\mathrm{A} 10}$ & 67.5 & 80.3 \\
\hline \multicolumn{3}{|c|}{ Impulsiveness, $I$} \\
\hline$I_{90}$ & 0.1 & 7.4 \\
\hline$I_{50}$ & 0.3 & 10.6 \\
\hline$I_{10}$ & 2.1 & 16.4 \\
\hline
\end{tabular}


The big difference between indicators $L_{\mathrm{A} 90}$ and $L_{\mathrm{A} 10}$ indicates a large spread of results (instantaneous A levels) for passing through the railroad switches. For a typical ride, the difference between parameters $L_{\mathrm{A} 90}$ and $L_{\mathrm{A} 10}$ is very small, just a several of decibels. There is also a wide quantitative diversity in the impulsiveness parameter, which is comprehensible, because impulsive sounds practically do not occur during typical rides.

\section{Conclusions}

Equivalent sound level $L_{\text {Aeq }}$ calculated for the typical ride differs from the rating sound level of ride through a railroad switch by $6-8 \mathrm{~dB}$. Despite the small differences, the noise generated in the second type of ride is more burdensome due to the characteristic "knocks", reaching at the time of impact level of up to $90 \mathrm{~dB}$. These "knocks" are placed in a band from 1600-2000 Hz. Spectral analysis of the acoustic signal indicates that the highest intensity of noise occurs in the sensitive for hearing bands: $400 \mathrm{~Hz}, 1250 \mathrm{~Hz}$ and in the bands adjacent to them. These are the bands corresponding to noise rolling and noise impact of a wheel and loose rail.

Each of the proposed descriptors can be used to identify this phenomenon: Shifted spectral centroid indicates the presence of "knocks" components. Kurtosis can be used as an additional parameter, according to the poor identification of impulsive events for the railbuses. Finally, the high value of impulsiveness, calculated both for the entire ride, and for short periods of time gives a quantitative assessment of the occurrence of impulses and may be the basis for qualifying that events for one of the three categories of impulse noise sources.

Therefore, it can be concluded that the difference in levels $L_{\mathrm{A} 90}$ and $L_{\mathrm{A} 10}$ can be used in the identification of different types of passages, and furthermore, what is important especially for the descriptor of impulsiveness $I$, values of quantity dependencies can be significant for deciding of the value of impulsive adjustment, but more studies should be conducted.

Proposed descriptors are useful in determination of impulsive noise appearance. Furthermore, they can be useful for automatic identification of fragments which contain noise impulses and for applying proper value of impulsive adjustment, especially in systems of continuous noise monitoring.

\section{References}

1. Berry B.F., Bisping R. (1988), CEC joint project on impulse noise: Physical qualification methods, Proceedings of 5th International Congress on noise as a public Health Problem, pp. 153-158, Stockholm.

2. Directive 2002/49/EC of the European Parliament and of the Council of 25 June 2002 relating to the assessment and management of environmental noise.

3. Hamernik R.P., Hsueh K.D. (1991), Impulse noise: some definitions, physical acoustics and other considerations, The Journal of the Acoustical Society of America, 90, 1, 189-196.

4. ISO 1996-1:2016: Acoustics - Description, measurement and assessment of environmental noise - Part 1: Basic quantities and assessment procedures.

5. ISO 1996-2: 2007: Acoustics - Description, measurement and assessment of environmental noise - Part 2: Determination of environmental noise levels.

6. Kukulski B. (2013), Parameterization and evaluation of the noise from rail commuting during approaching the station [in Polish], Engineer Thesis, WIMIR AGH, Kraków.

7. Regulation of the Minister of Environment dated 16 June 2011 (Official Journal No. 140, Item 824).

8. Regulation of the Minister of Environment dated 30 October 2014 (Official Journal, Item 1542).

9. Thompson D. (2009), Railway noise and vibration: Mechanics, modelling and means of control, Elsevier, Oxford.

10. VERHEIJEN E. (2004), Using source separation techniques in measuring railway noise emission, Proceedings of Conference Inter-Noise, Prague.

11. Verheijen E., Paviotti M. (2003), VTN: A validated method to separate track and vehicle noise and to assess noise reduction measures, World Congress on Railway Research conference materials, Edinburgh.

12. WszoŁeK T. (2015), Tonal and Impulsive adjustment for Noise Source Rating Levels, Progress of Acoustics, Polish Acoustical Society, Wroclaw Division, 2015, pp. $413-426$.

13. Wszolek T., Koter M. (2015), Parametrization and assessment of curve and brake squeal from train approaching to the station, Przegląd Mechaniczny, No 7-8, pp. 28-42. 